\title{
Inclusive Growth through Inclusive Governance in India's North East
}

\author{
Commonwealth Journal of Local Governance \\ Issue 2: January 2009
}

http://epress.lib.uts.edu.au/ojs/index.php/cjlg

\section{Mani Shankar Aiyar and Nupur Tiwari}

Ministry of Panchayati Raj and

DoNER, ${ }^{1}$ Government of India
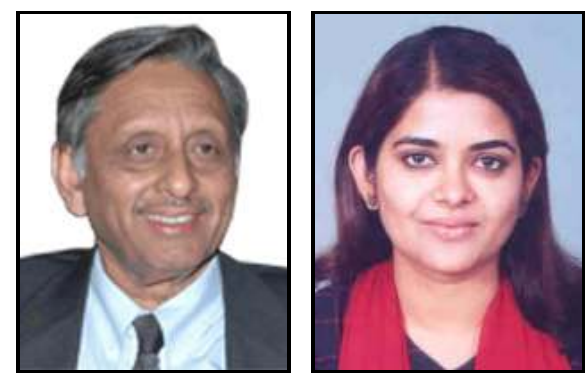

\section{Introduction}

'Inclusive Growth' is both the title and the overarching goal of the Eleventh Five Year Plan of India. ${ }^{2}$ Economic reforms have led, especially over the last five years or so, not only to accelerated growth but to sustained accelerated growth. Yet, notwithstanding the considerable space given to Panchayati Raj ${ }^{3}$ in the Eleventh Plan, there still seems to be some reluctance to accept inclusive governance as the quintessential and unique path to inclusive growth.

There is no doubt that the acceleration of growth on a sustained basis combined with major tax reforms has resulted in a miraculous augmentation of government revenues, particularly over the last four years. This has resulted in buoyant spending on the social sector. In his recent address to the National Convention, the Prime Minister estimated the increased spending on poverty alleviation and rural development at four times that of the last year of the previous government. In

\footnotetext{
${ }^{1}$ Ministry of Development of the North Eastern Region.

${ }^{2}$ Editors note: India's five years plans are framed, executed and monitored by the Planning Commission. See <http://planningcommission.nic.in>.

3 Editors note: Panchayati Raj Institutions (PRIs) are units of local self-government. There are three levels of panchayat - village, intermediate, and district. See 'Decentralization and Strengthening Panchayati Raj Institutions (PRIs)' in Chapter X: Governance, Eleventh Five- Year Plan 2007-12.
} 
absolute numbers, this represents an increase (in nominal terms) from around Rs.34,000 crore $^{4}$ in fiscal 2003-04 to about Rs.120,000 crore in the current financial year. Moreover, this increase comes on top of growth in such spending between 1993-94 and 2003-04, in nominal terms, from about Rs.7600 crore to about Rs.34,000 crore.

Why, then, is there such a mismatch between growth in the booming sectors of our economy and the income of the entrepreneurial classes, in contrast to the uncertain, sporadic and un-sustained condition of the vast majority of Indians? Why is India prospering when most Indians are not?

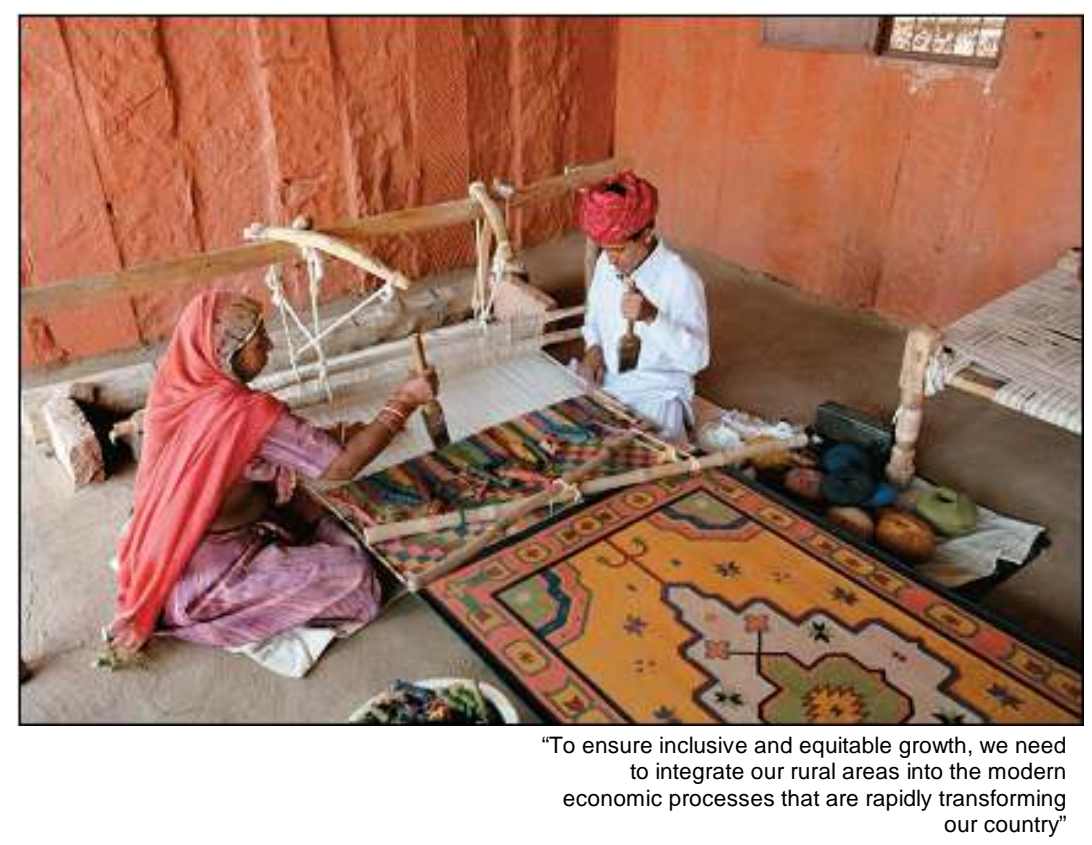

In August 2007, the Arjun Sengupta Committee (http://nceus.gov.in) reported the deeply disturbing yet widely accepted figure of 836 million Indians - over $75 \%$ of our people - as being 'poor and vulnerable', surviving on an average expenditure of under Rs.20 per day. This is the equivalent of what a family of four earns per capita as the daily wage in Tamil Nadu under the National Rural Employment Guarantee Programme. ${ }^{5}$

Although over the last four years India has witnessed a sustained GDP growth rate of 8.8 per cent per annum, which is set to rise even higher, poverty levels remain unacceptably high. More than 300 million people in India still live in deep poverty at less than a dollar a day, while another 350 million live on less than two dollars a day. In this sense, the rich-poor divide has increased and poverty reduction figures for India are

\footnotetext{
${ }_{5}^{4}$ An Indian crore equals 10 million.

${ }^{5}$ Incidentally, the NREGP wage rate in Tamil Nadu is just about the highest in the country. For more information, visit: 〈http://nrega.nic.in>.
} 
now lower than those of Bangladesh. There are also disparities among regions, states, sectors and communities. Among the states, the North Eastern Region as a whole and the Central regions, which have large tribal populations, are lagging behind. Among sectors, agriculture has fallen behind industry and the service sector.

The key component of our 'strategy of inclusive growth' must be inclusive governance as the means of empowering the disadvantaged, with the aim of enabling them to overcome their poverty. It is the effective empowerment of the disadvantaged through the effective devolution of functions, finances and functionaries to the representative institutions of local self-government on the principle of subsidiarity (which states that anything which can be done at a lower level should be done at that level and no higher level), that will pave the way to the effective implementation of other measures of inclusive growth. These include:

- Stepping up investment in rural areas, in rural infrastructure and agriculture

- Increased credit availability, particularly to farmers and others, and offering them remunerative prices for their crops

- Increased rural employment, including the provision of a unique social safety net in the shape of the National Rural Employment Guarantee Programme

- Increased public spending on education and health care, including strengthening the midday meal programme and offering scholarships to the needy

- Investment in urban renewal, improving the quality of life for the urban poor

- Empowering the scheduled castes, scheduled tribes, other backward classes, minorities, women and children, socially, economically and educationally

- Ensuring that, through public investment, the growth process spreads to backward regions and districts of our country. ${ }^{6}$

Local self-government, as elaborated in our Constitution, provides the essential means of reconciling 'accelerated growth' with 'inclusive growth', and we cannot secure inclusive growth without inclusive governance. The virtually three-fold increase in annual allocations to rural development and welfare, and the launching of new schemes like NREGA, BRGF and RTI, ${ }^{7}$ are not inadequately impacting on the concept of inclusive growth because governance at the grassroots is still far from inclusive. In addition, too large a proportion of the central government's annual expenditure of Rs.81,000 crore on rural development and welfare reaches the people - if at all - through government-run or officially managed silos, whilst too small a proportion of it is actually planned and implemented with the participation, involvement and supervision of village communities and their elected

\footnotetext{
${ }^{6}$ Based on the foreword by the Prime Minister, Dr. Manmohan Singh, in Report to the People 2004 2008, UPA Government. See: http://pib.nic.in/archieve/upareport/report2008.pdf [7.39MB]

${ }^{7}$ Respectively, the National Rural Employment Guarantee Act (http://nrega.nic.in); the Backward Regions Grant Fund (http://brgf.gov.in), and the Right to Information Act (http://rti.gov.in).
} 
representatives. Frustration can emerge if Gram Sabhas ${ }^{8}$ are largely nonfunctional, and if most elected representatives (other than Panchayat presidents) are left uninvolved, particularly when they see more and more money being poured into rural areas with much of it beyond their control or responsibility. This can undermine the overarching components of governance such as policy formulation, implementation and monitoring and evaluation.
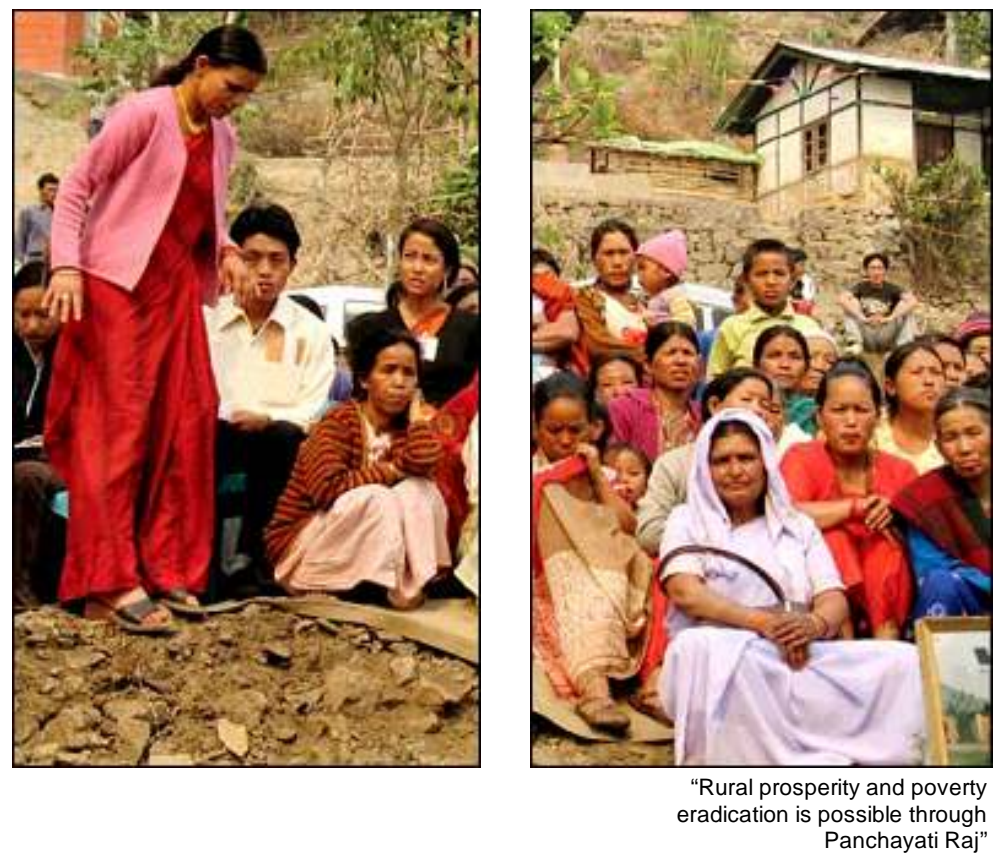

This lack of involvement is incongruous considering that the Constitutional amendments have so firmly rooted Panchayati Raj in our system of governance. Today, 3.2 million elected representatives, including 1.2 million women and well over $22 \%$ from scheduled castes and scheduled tribes (their estimated share in the rural population), serve in these grassroots local bodies of our vibrantly democratic society. There are two reasons for this anomaly: firstly, a lack of effective devolution of functions, finances and functions by state legislatures/governments to the Panchayati Raj Institutions (PRIs); and secondly, inadequate provisions for planning and implementation through PRIs in the guidelines issued by central ministries for centrally sponsored and central sector schemes. Both directly impinge on inclusive growth. To reinforce economic reform and secure inclusive growth it is important that Panchayati Raj be brought centre-stage as the principal governance reform. Also, parallel measures for empowering the grassroots are required in those areas that the Constitution exempts from the Panchayati Raj system, such as the Sixth Schedule areas and much of the North Eastern Region.

\footnotetext{
${ }^{8} \mathrm{~A}$ bi-annual village meeting of all persons aged 18 years or more, which considers development schemes and reviews the work of the Panchayat.
} 
Activating and strengthening institutions of local self-government requires adherence to certain broad and generally well-accepted principles of institutional design. Some of the features of a good design for local self-government include:

- Conducting regular elections for local bodies

- Clarity in the functional assignments to different levels of local bodies in rural and urban areas

- Matching the devolution of functions with the concomitant devolution of funds and functionaries so that the devolved functions might be effectively performed

- Ensuring that elected representatives of local bodies effectively wield powers

- Building capacity in local bodies to undertake planning

- Ensuring a healthy, constructive and mutually fruitful relationship between officials appointed by the state government and elected local bodies

- Providing for collective decision-making through Gram and Ward Sabhas and holding the local body to account for its performance.

In addition, it is important to create appropriate systems and institutions for planning and delivery of public services, including information systems, as well as for monitoring and evaluation and ensuring accountability.

\section{Inclusive Governance in the North Eastern Region}

Systems of decentralised governance in the North Eastern Region show a wide diversity due to ethnic, linguistic and religious variance unparalleled in any other region of the country. While the Panchayati Raj system (Part IX of the Constitution) fully covers two of the eight states of the region - Sikkim and Arunachal Pradesh, three other states (Mizoram, Meghalaya and Nagaland) are entirely exempted and have their own local systems. The remaining three (Assam, Tripura and Manipur) have both Panchayati Raj and non-Panchayati Raj areas existing side by side. Furthermore, although Sikkim, Arunachal Pradesh and parts of Assam, Tripura and Manipur are covered under the provisions of Part IX of the Constitution, the extent of powers devolved upon Panchayats in these states is uneven. Such diversity is healthy and to be encouraged even though it makes local governance exceedingly complex, since it reflects the immense ethnic, linguistic and religious diversity seen in the region.

Some positive outcomes are as follows:

- Sikkim has been adjudged the third best state in the country in the implementation of Panchayati Raj

- Assam has been judged the best for activity mapping ${ }^{9}$

\footnotetext{
${ }^{9}$ Activity mapping is a process required under the Constitution as part of devolving powers to PRIs. It is undertaken by central government departments in order to allocate functional responsibilities among the three tiers of Panchayati Raj.
} 
- Tripura and Manipur are among the better states for their pattern of devolution

- Arunachal Pradesh has been commended for recent steps taken to move towards effective devolution.

In all five states there is considerable scope for advancing the cause of devolution. Happily, all five are party to the 150 conclusions of the seven Round Table Conferences held in 2004 covering all eighteen identified dimensions of Panchayati Raj. Those conclusions were reinforced by Memoranda of Understanding or joint Statements of Conclusions signed by the Chief Ministers and the Union Minister of Panchayati Raj, including agreed state-specific action points. Accelerated implementation by state and central governments of these agreed action points will contribute greatly to securing inclusive growth through inclusive governance in the North-East Region. A common feature of these diverse systems of self-governance is that all need strengthening. This is as true of the North East as it is of most parts of the country.

\section{Progress in the Five States}

Sikkim has completed activity mapping, including detailed assignment of funds to Panchayats and of the officials who will be attached to each Panchayat for the performance of devolved activities.

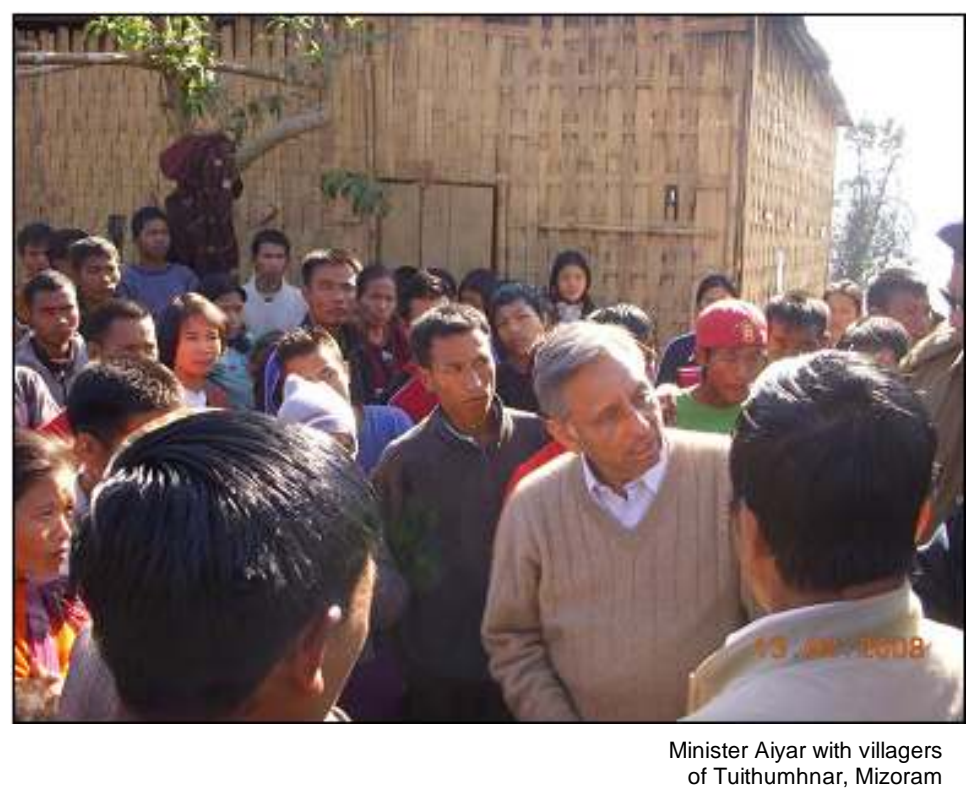

The Arunachal Pradesh Activity Mapping Order 2007 was issued in October 2007 and the executive order for devolution of 29 subjects of activity mapping subsequently issued in February, 2008, covering 20 government departments. There is overlap of some of the functions devolved to different tiers of Panchayats and more clarity is required to specify devolved functions in terms of policy, planning, implementation, and coordination and control. Furthermore, the relevant 
government functionaries (officials) have yet to be transferred to Panchayats, although the Directorate of Panchayati Raj has initiated the process in consultation with the departments concerned.

Assam has 21 districts covered under Part IX of the Constitution whilst other areas fall under the Sixth Schedule. The Government of Assam issued a notification in June 2007 through which functions, functionaries and funds in respect of 23 subjects were devolved to the three tiers of the Panchayats. The responsibilities of each tier are clearly demarcated and these have been distributed according to the capacity of each level of Panchayat. The activity mapping also indicates in detail the staff transferred to the Panchayats and the accounts from which funds will be drawn for the activities assigned to the Panchayats. However, elections to the Panchayats in Assam were held in December 2007 and it is still to be seen whether the notification regarding activity mapping has been effectively implemented.

The Manipur Panchayati Raj Act of 1994 details the intended devolution of functions to the PRIs, covering all 29 items listed in Schedule 11 of the Constitution. However, activity mapping approved by the state cabinet in September 2005 lists only 16 of these items, and no funds and functionaries have been devolved. Whilst the state government has undertaken to transfer all functionaries along with functions and finances to the Panchayats, and to frame rules for Panchayat-based cadres of technical and other support services recruited at the Panchayat level, there is no visible progress in this regard.

In Tripura, activity mapping was completed in 2005. This also covered the 29 items listed in the $11^{\text {th }}$ Schedule and applies to 21 departments. The government of Tripura has taken a decision to implement the activity mapping in phases. To date, irrigation schemes, primary schools and institutions relating to the Ministry of Women and Child Development (WCD) have been transferred to the Panchayats through executive orders. Functionaries for five items from the $11^{\text {th }}$ Schedule have been devolved to Panchayats, who review their work and have the power to recommend payment of salary, transfers, grants of leave and disciplinary action. However, overall controlling authority remains with the line departments and the state has continued to recruit further staff after devolving functionaries to Panchayats.

All five States will need to clearly identify those budgetary items that ought to go to the Panchayats and to separately earmark them through a Panchayat sector window in the budgets of the relevant line departments. This will ensure the flow of funds required for undertaking devolved activities. Functionaries will need to be devolved to the appropriate level of the Panchayati Raj system to reflect any given activity assigned in the activity map, and in conformity with the pattern of devolution of functions and finances. These are all works in progress and activity in this regard over the last few years has been encouraging. The stage is, therefore, well and truly set for 'inclusive growth through inclusive governance' provided this is given priority and followed through assiduously and conscientiously. 
Institutionalising participative planning from the grassroots level in the preparation of a district plan is another key step in the strengthening of Panchayats. As mandated in the Constitution, $80 \%$ of the members of District Planning Committees (DPCs) are required to be elected by and from amongst the elected members of the district level Panchayat (Zilla Parishad) and the municipalities within the district. Although most of the five states falling under Part IX of the Constitution now have DPCs with constitutions, in Arunachal Pradesh and Tripura some issues relating to the composition of the DPCs still remain to be clarified, owing to special circumstances.

The district plan must emerge from plans prepared by each village Panchayat, intermediate Panchayat, district Panchayat and municipality for their respective geographical areas and functional competencies. To this end, state governments need to clearly inform Panchayats at each level (and the municipalities) about the resources likely to be available and the activities entrusted to them. DPCs have the responsibility of 'consolidating' these local plans into a draft district development plan and forwarding it to the state government.

The North Eastern Region states concerned have commenced the process of district planning through the Panchayats in districts covered by the Backward Regions Grant Fund. However, steps will need to be taken to ensure that these guidelines are fully followed and district planning is established as a practice in all districts in the region.

We must put an end to planning from above. We must put an end to priorities being conceived and decided at ethereal heights, far removed from the realities on the ground. We must initiate a process of people's planning. (Shri Rajiv Gandhi)

\section{Governance Reforms in Exempt Areas}

All of Meghalaya and Mizoram, and large tracts of Tripura, come under the provisions of the Sixth Schedule to the Constitution. Nagaland and the hill areas of Manipur are governed by similar arrangements through state legislation. Such special arrangements are aimed at the protection of tribal areas and interests, by mandating district or regional local self-government institutions entrusted with the dual tasks of protecting tribal culture and customs, and undertaking development activities. However, unlike their Panchayati Raj counterparts, the Autonomous Developmental Councils that are supposed to establish responsive administrations and undertake development planning functions (with maximum participation of the people), are yet to fulfil their role effectively.

In order to maximize people's participation in governance and to chart a clear roadmap to involve these institutions in grassroots planning, the Ministry of Panchayati Raj appointed an Expert Group on Grassroots Planning for the Sixth Schedule Areas (and those areas not covered by Parts IX and IXA of the Constitution). The Expert Group has suggested a series of sequential steps for 
building the district plan. First, a district vision that sets out the goals and outcomes for the next 10-15 years will need to be fashioned through participative processes starting from the grassroots level upwards. Each planning unit should then articulate the vision and set out goals and outcomes in terms of human development indicators, infrastructure development and development in the productive sectors of the economy, based on available physical and human resources.

\section{Conclusion}

While the Constitution leaves it to the states to determine the nature, direction and pace of devolution, there is a crying need to motivate the states to further empower their PRIs, and also to provide incentives for PRIs to be transparent and accountable in their transactions. As the Eleventh Five Year Plan states:

...there is a need to build in incentives that will encourage the States to devolve functions, funds and functionaries to the PRIs. In order to capture the extent to which this process and empowerment of PRIs has actually progressed in a State, a suitable devolution index will be developed and will be called the PRI-

Empowerment Index. (para 1.148)

Central government could greatly accelerate and rationalise this process by adapting the guidelines of Central Sector and Centrally Sponsored Schemes (the principal sources of funding for PRIs), to ensure the importance of PRIs in the planning and implementation of these schemes in conformity with the letter and spirit of the Constitution.

There is also an imperative to make available untied block grants to the PRIs so that they have an adequate reservoir of financial resources to plan and implement neighbourhood economic development and social justice programs, as envisaged in Parts IX and IXA. The $13^{\text {th }}$ Finance Commission (http://fincomindia.nic.in) has a golden opportunity to build on the tentative beginnings of previous Commissions by increasing untied grants, particularly for maintenance of community assets and improved service delivery.

We continue to rely heavily on a creaking bureaucratic delivery system, fashioned into administrative silos, which over six decades has proved to be quite unequal to the task of delivering development. The Eleventh Five Year Plan says:

\footnotetext{
The DRDAs (District Rural Development Agencies, the bureaucratic arm of the Ministry of Rural Development) in their current form and content do not appear to have the requisite wherewithal to handle a complex issue such as poverty. The current administrative set up at the national level is unequal to a large task such as poverty elimination across geographical and social complexity... (para 4.70)
}

Our need is not bureaucratic development but participative development, that is, grassroots development through grassroots democracy. The path to such development was charted through the $73^{\text {rd }}$ and $74^{\text {th }}$ amendments to the Constitution which resulted in the present Part IX ('The Panchayats') and Part IXA ('The 
Municipalities'). In these two parts of the Constitution we have the key to inclusive growth through inclusive governance. For inclusive growth, we need to hitch the horse of accelerated growth to the wagon of participative development. 